\title{
Relationship between admission coagulopathy and prognosis in children with traumatic brain injury: a retrospective study
}

Cheng-yan You ${ }^{1,2,3,4,5}$, Si-wei Lu' ${ }^{1,2,3,4,5}$, Yue-qiang Fu ${ }^{1,2,3,4,5^{*}}$ and Feng $\mathrm{Xu}^{1,2,3,4,5}$

\begin{abstract}
Background: Coagulopathy in adult patients with traumatic brain injury (TBI) is strongly associated with unfavorable outcomes. However, few reports focus on pediatric TBI-associated coagulopathy.

Methods: We retrospectively identified children with Glasgow Coma Scale $\leq 13$ in a tertiary pediatric hospital from April 2012 to December 2019 to evaluate the impact of admission coagulopathy on their prognosis. A classification and regression tree (CART) analysis using coagulation parameters was performed to stratify the death risk among patients. The importance of these parameters was examined by multivariate logistic regression analysis.

Results: A total of 281 children with moderate to severe TBI were enrolled. A receiver operating characteristic curve showed that activated partial thromboplastin time (APTT) and fibrinogen were effective predictors of in-hospital mortality. According to the CART analysis, APTT of $39.2 \mathrm{~s}$ was identified as the best discriminator, while $120 \mathrm{mg} / \mathrm{dL}$ fibrinogen was the second split in the subgroup of APTT $\leq 39.2 \mathrm{~s}$. Patients were stratified into three groups, in which mortality was as follows: $4.5 \%$ (APTT $\leq 39.2 \mathrm{~s}$, fibrinogen $>120 \mathrm{mg} / \mathrm{dL}$ ), $20.5 \%$ (APTT $\leq 39.2 \mathrm{~s}$ and fibrinogen $\leq 120 \mathrm{mg} / \mathrm{dL}$ ) and $60.8 \%$ (APTT > $39.2 \mathrm{~s}$ ). Furthermore, length-of-stay in the ICU and duration of mechanical ventilation were significantly prolonged in patients with deteriorated APTT or fibrinogen values. Multiple logistic regression analysis showed that APTT > 39.2 s and fibrinogen $\leq 120 \mathrm{mg} / \mathrm{dL}$ was independently associated with mortality in children with moderate to severe TBI.

Conclusions: We concluded that admission APTT> $39.2 \mathrm{~s}$ and fibrinogen $\leq 120 \mathrm{mg} / \mathrm{dL}$ were independently associated with mortality in children with moderate to severe TBI. Early identification and intervention of abnormal APTT and fibrinogen in pediatric TBI patients may be beneficial to their prognosis.
\end{abstract}

Keywords: Children, Activated partial thromboplastin time, Fibrinogen, Prognosis, Traumatic brain injury

\footnotetext{
* Correspondence: 480887@hospital.cqmu.edu.cn

'Department of Critical Care Medicine, Children's Hospital, Chongqing

Medical University, 136\# Zhongshan Er Road, Yu Zhong District, 400014 Chongqing, People's Republic of China

${ }^{2}$ Ministry of Education Key Laboratory of Child Development and Disorders, 400014 Chongqing, People's Republic of China

Full list of author information is available at the end of the article
} 


\section{Introduction}

Traumatic brain injury (TBI) is one of the leading causes of trauma-induced mortality and disability in children and adolescents [1]. Coagulation dysfunction is frequently observed following TBI, especially in patients with severe TBI [2-4]. Although there is a trend toward increased use of dynamic hemostatic assays such as thromboelastography (TEG), coagulopathy is still commonly diagnosed by routine coagulation laboratory tests, including the International normalized ratio (INR), activated partial thromboplastin time (APTT) and others, in developing countries.

Current research revealed that abnormalities in routine coagulation laboratory tests upon admission were strong predictors of poor outcomes in patients with TBI [5-8]. Albert et al. [8] reported that the mortality of TBI patients with admission coagulopathy, defined by a prolonged INR, prothrombin time (PT) or APTT, was significantly higher than that of the no-coagulopathic group. Kelly et al. [6] demonstrated that D-dimer elevation upon admission was significantly associated with progression of intracranial hemorrhage (PICH), which is a major cause of secondary brain injury and a worse outcome after TBI.

However, there are relatively few reports focused on coagulation abnormalities in children with TBI. In one comparative study that included pediatric and adult trauma patients, Strumwasser et al. [9] reported that TBI-related coagulopathy increased in a stepwise fashion with age. Dwivedi et al. [3] found that coagulopathy was present in $37.5 \%$ of the pediatric TBI group and $68.03 \%$ of the adult group, and there was a high mortality rate in the coagulopathy group in both the adult and pediatric populations (63.04 and $50 \%$, respectively). However, it is noteworthy that the population of the pediatric TBI group in their study was relatively small $(n=48)$ [3]. Whittaker et al. [10] found that early coagulopathy was associated with a modest increase in mortality in pediatric trauma patients without TBI, whereas it was associated with a four-fold increase in mortality among TBI patients. Importantly, coagulopathy in this study was only defined by an INR of 1.2 or greater [10], ignoring the impact of other coagulation parameters. The impact of coagulopathy on children with TBI may be different from that of the adult population and pediatric trauma patients without TBI. Moreover, due to the heterogenic definition of coagulopathy and cutoff values used, the relationship between admission coagulopathy and clinical outcomes in children with TBI remains to be established.

In this study, we aim to evaluate the predictive value of admission coagulation parameters on the prognosis of children with moderate to severe TBI. We hypothesized that the admission coagulation parameters were associated with increased in-hospital mortality, length-of-stay in the ICU and duration of mechanical ventilation in children with moderate to severe TBI.

\section{Methods \\ Study design and participants}

We retrospectively identified all pediatric patients younger than 18 years with moderate to severe TBI [Glasgow Coma Scale $(\mathrm{GCS}) \leq 13$ ] who were admitted to the intensive care unit (ICU) at the Children's Hospital of Chongqing Medical University in Chongqing, China, from April 2012 to December 2019. Ethical approval was obtained from the Institutional Ethics Review Board of Children's Hospital, Chongqing Medical University. The need for informed consent was waived due to the anonymous and observational nature of this study. The exclusion criteria of the study were as follows: older than 18 years, injury occurred over $24 \mathrm{~h}$ of admission, blood product transfusion prior to sample collection, history of a hemorrhagic disorder, anticoagulant medication before presentation at the Emergency Department.

\section{Study parameters and definitions}

Blood samples were collected immediately upon arrival at the emergency department. The demographic and clinical information collected included age; gender; weight; mechanism of injury; TBI lesion type; admission GCS score; Abbreviated Injury Scale (AIS); Injury Severity Score (ISS); Pediatric Trauma Score (PTS); systolic blood pressure (SBP); routine laboratory investigations, such as lactate level, INR, APTT, thrombin time (TT), fibrinogen, platelet count (PLT), D-dimer level, white blood cell (WBC) count and hemoglobin (Hgb) level; length of stay (LOS) in the ICU and hospital; duration of mechanical ventilation; and mortality.

The Pediatric Trauma Score (PTS) was developed as a means of providing a rapid accurate assessment of the severity of injury of an injured child and includes weight, airway, SBP, central nervous system, open wound and skeletal states [11]. Hypotension was defined as an admission SBP $<70$ $\mathrm{mmHg}$ for infants younger than 1 year, $\mathrm{SBP}<70+(2 \times a g e)$ $\mathrm{mmHg}$ for patients aged from 1 to 10 years and SBP $<90$ $\mathrm{mmHg}$ for children aged 11 years and older [12]. Polytrauma was defined as AIS head $\geq 3$ with one other AIS region $\geq 3$. Abnormal pupil was defined by abnormalities in pupil size, symmetry, or pupillary light reactivity.

\section{Management of TBI}

During hospitalization, TBI patients were given routine care for head trauma, as follows: Midazolam and phenobarbital sodium were used for sedation and sufentanil for analgesia; hyperosmolar medication (mannitol, glycerol fructose, hypertonic saline) was administered to reduce intracranial pressure when needed; temperature 
was controlled to avoid hyperthermia using temperature-regulating blankets; and neurosurgical interventions were performed, including monitoring of intracranial pressure, external ventricular draining, evacuation of hematoma, dissection of necrotic brain tissue, decompressive craniectomy and reduction of separation-fracture.

\section{Outcomes}

The primary outcome measure was post-trauma mortality that occurred in the hospital. The secondary outcome measures were duration of mechanical ventilation and length of stay (LOS) in the ICU and hospital. To account for death as a competing outcome, we considered the need for mechanical ventilation as ventilator-free days with a maximum of 14 days. For LOS, we used ICU- and hospital-free days with maximums of 14 and 28 days, respectively.

\section{Statistical analysis}

All data analyses were performed using the IBM SPSS Statistics for Windows, version 23.0 (IBM Corp, Armonk NY, USA). Receiver operating characteristic (ROC) curves were calculated using Medcalc (version 19.0.7 Ostend, Belgium). Baseline characteristics were compared between survivors and non-survivors during the hospital stay. Continuous variables are expressed as the median and interquartile range (IQR) and were compared using the Mann Whitney U-test for two groups or the Kruskal-Wallis $\mathrm{H}$ test for more than two groups. Categorical variables are expressed as percentages, and the Chi-Square test/Fishers test was performed to compare proportions. A $p$ value of $<0.05$ was considered statistically significant.

ROC curves were used to assess the predictive performance of routine coagulation parameters for mortality in the overall TBI group and the subgroup of isolated TBI. The classification and regression tree (CART) is a predictive model used to explore variables that exist as multicollinearity problems by selecting only one variable as the most important discriminator, and it has become increasingly popular in the medical field [13]. Considering this, we performed a CART analysis to investigate which coagulation parameters best predicted mortality risk and their optimal cut-off values. Finally, based on the cut-off value from the CART analysis, multivariate logistic regression analysis was performed to identify risk factors independently associated with mortality after adjusting for other factors that were significant at $p<0.05$.

\section{Results}

\section{Clinical characteristics}

A total of 281 children with moderate to severe TBI were enrolled. Of these children, 53 (18.9\%) died in the hospital. The baseline and clinical characteristics of the survivors $(n=228)$ and non-survivors $(n=53)$ in the overall group and the isolated TBI group are summarized respectively in Tables 1 and 2. Males comprised $60.5 \%$ of the total study population. Survivors had significantly a higher GCS and PTS than non-survivors $(p<0.05)$ in both the overall group and isolated TBI group, which indicated that the injury severity was closely associated with death. However, the comparison of ISS between survivors and non-survivors in the isolated TBI group was of no significance, which may due to the relative mild damage to other parts of the body in the isolated TBI group. Fall was the leading cause of TBI in both the overall group and the isolated TBI group (135, $48.0 \%$ and $63,46.0 \%$ respectively), the rest of the causes of the TBI cases were road traffic accidents (109, $38.8 \%$ and $43,31.4 \%$ respectively) and others. The most common intracranial lesions in the enrolled patients in decreasing order of frequency were as follows: subarachnoid hemorrhage (137, $48.8 \%)$, contusion (125, $44.5 \%)$, subdural hemorrhage $(98,34.9 \%)$, extradural hemorrhage $(82, \quad 29.2 \%)$ and intraparenchymal hemorrhage (42, $14.9 \%)$.

One hundred forty-four (51.2\%) patients presented with polytrauma. Compared with survivors, non-survivors showed significantly higher rates of hypotension and abnormal pupil at admission in the overall group $(28.3 \%$ vs. $8.3 \%, 88.7 \%$ vs. $27.2 \%$ ). While in the subgroup of isolated TBI patients, the incidence of admission hypotension in non-survivors and survivors was of no significance (15.8\% vs. $7.6 \%, p=0.373)$. The baseline admission lactate level, INR and APTT were significantly higher in non-survivors than survivors in both the overall group and the subgroup of isolated TBI patients, while the reverse was true of the fibrinogen level and $\mathrm{Hgb}$ concentration. The platelet count was significant decrease in the overall group $(p=$ 0.006), but this change was not observed in the subgroup of isolated TBI patients $(p=0.830)$. However, the D-dimer level and WBC count were not significantly elevated in non-survivors compared to survivors in both the overall group and the isolated TBI group.

According to the comparisons of demographics and clinical data in patients with isolated TBI and polytrauma in Table 3, we found that the age, weight, and severity of injury in polytrauma patients were significantly greater than isolated TBI patients, and the incidence of traffic and fall was greater than patients in isolated TBI group. This may due to the relatively wider range of activities among elder children. Compared with the isolated TBI patients, the percentage of abnormal pupil, the level of admission lactate, INR, APTT, D-dimer were significantly elevated in children with polytrauma, and the level of fibrinogen and platelet was 
Table 1 Demographics and clinical data of all TBI patients by survivors and non-survivors

\begin{tabular}{|c|c|c|c|c|}
\hline & $\begin{array}{l}\text { All patients } \\
(n=281)\end{array}$ & $\begin{array}{l}\text { Survivors } \\
(n=228)\end{array}$ & $\begin{array}{l}\text { Non-survivors } \\
(n=53)\end{array}$ & $P$ value \\
\hline \multicolumn{5}{|l|}{ Baseline Demographics } \\
\hline Age, M & $50.0(19.5-87.0)$ & $51.0(20.3-87.0)$ & $49.0(18.0-85.5)$ & 0.678 \\
\hline Weight, kg & $17.0(11.3-24.0)$ & $17.5(11.0-25.0)$ & $15.0(12.0-21.3)$ & 0.419 \\
\hline Gender, male, n (\%) & $170(60.5 \%)$ & $141(61.8 \%)$ & $29(54.7 \%)$ & 0.339 \\
\hline \multicolumn{5}{|l|}{ Injury severity } \\
\hline GCS & $8(6-10)$ & $8(7-11)$ & $5(3-7)$ & $<0.001$ \\
\hline PTS & $5(3-7)$ & $5(3-7)$ & $2(1-4)$ & $<0.001$ \\
\hline ISS & $18(13-27)$ & $18(9-25)$ & $25(18-30)$ & 0.003 \\
\hline Mechanism of injury & & & & 0.505 \\
\hline Traffic, n (\%) & $109(38.8 \%)$ & $92(40.4 \%)$ & $17(32.1 \%)$ & \\
\hline Fall, n (\%) & $135(48.0 \%)$ & $106(46.5 \%)$ & $29(54.7 \%)$ & \\
\hline Others, n (\%) & $37(13.2 \%)$ & $30(13.2 \%)$ & $7(13.2 \%)$ & \\
\hline \multicolumn{5}{|l|}{ Lesion type } \\
\hline $\mathrm{EDH}, \mathrm{n}(\%)$ & $82(29.2 \%)$ & $74(32.5 \%)$ & $8(15.1 \%)$ & 0.018 \\
\hline $\mathrm{SDH}, \mathrm{n}(\%)$ & $98(34.9 \%)$ & $78(34.2 \%)$ & $20(37.7 \%)$ & 0.476 \\
\hline SAH, n (\%) & $137(48.8 \%)$ & $106(46.5 \%)$ & $31(58.5 \%)$ & 0.057 \\
\hline Contusion, n (\%) & $125(44.5 \%)$ & $102(44.7 \%)$ & $23(43.4 \%)$ & 0.932 \\
\hline Intraparenchymal hemorrhage,n(\%) & $42(14.9 \%)$ & $36(15.8 \%)$ & $6(11.3 \%)$ & 0.477 \\
\hline Polytrauma, n (\%) & $144(51.2 \%)$ & $110(48.2 \%)$ & $34(64.2 \%)$ & 0.037 \\
\hline Abnormal pupil, n (\%) & $109(38.8 \%)$ & $62(27.2 \%)$ & $47(88.7 \%)$ & $<0.001$ \\
\hline Hypotension, n (\%) & $34(12.1 \%)$ & $19(8.3 \%)$ & $15(28.3 \%)$ & $<0.001$ \\
\hline \multicolumn{5}{|l|}{ Laboratory investigations } \\
\hline Lactate, mmol/L & $2.1(0.8-4.0)$ & $1.5(0.8-3.2)$ & $4.6(2.9-7.0)$ & $<0.001$ \\
\hline INR & $1.16(1.07-1.34)$ & $1.14(1.05-1.26)$ & $1.49(1.21-1.94)$ & $<0.001$ \\
\hline APTT, s & $29.4(26.0-35.3)$ & $28.6(25.4-32.5)$ & $44.4(29.6-68.3)$ & $<0.001$ \\
\hline Fibrinogen, mg/dL & $\begin{array}{l}134.0 \\
(82.0-182.0)\end{array}$ & $\begin{array}{l}143.0 \\
(104.8-188.0)\end{array}$ & $\begin{array}{l}71.0 \\
(50.0-112.0)\end{array}$ & $<0.001$ \\
\hline$\pi, s$ & $18.7(17.3-21.3)$ & $18.3(17.1-20.3)$ & $22(18.8-30.1)$ & $<0.001$ \\
\hline D-dimer, ug/L & $\begin{array}{l}14,040 \\
(3965-22,865)\end{array}$ & $\begin{array}{l}13,665 \\
(3790-22,348)\end{array}$ & $\begin{array}{l}16,460 \\
(5280-29,695)\end{array}$ & 0.127 \\
\hline $\mathrm{PLT}, / \mathrm{UL}$ & $\begin{array}{l}261.0 \\
(200.0-324.0)\end{array}$ & $\begin{array}{l}264.5 \\
(208.3-331.3)\end{array}$ & $\begin{array}{l}210.0 \\
(158.0-298.0)\end{array}$ & 0.006 \\
\hline $\mathrm{Hgb}, \mathrm{g} / \mathrm{L}$ & $\begin{array}{l}98.0 \\
(81.5-111.0)\end{array}$ & $\begin{array}{l}101.0 \\
(84.3-113.0)\end{array}$ & $\begin{array}{l}85.0 \\
(68.0-102.0)\end{array}$ & $<0.001$ \\
\hline WBC, ${ }^{*} 10 \wedge 9 / L$ & 16.6(12.2-21.5) & $16.7(12.2-21.1)$ & $15.9(12.7-23.1)$ & 0.486 \\
\hline
\end{tabular}

Data are shown as the median (interquartile range) or a number (percentage)

$M$ month, GCS Glasgow Coma Score, PTS Pediatric Trauma Score, ISS Injury Severity Score, EDH epidural hemorrhage, SDH subdural hemorrhage, SAH subarachnoid hemorrhage, INR International normalized ratio, APTT activated partial thromboplastin time, $T$ Thrombin time, $P L T$ platelet count, $H g B$ hemoglobin, WBC white blood cell

significantly decreased in polytrauma patients. In addition, we found that the rate of hypotension, TT and Hgb concentration were of no significance in the two groups.

\section{ROC curve analyses of in-hospital mortality}

ROC curve analysis in the overall group (Table 4) showed that the INR (AUC $=0.770,95 \%$ CI: 0.716$0.818, p<0.001)$, APTT $(\mathrm{AUC}=0.781,95 \% \mathrm{CI}: 0.728-$
0.828, $p<0.001)$, TT $(\mathrm{AUC}=0.749,95 \% \mathrm{CI}: 0.694-0.798$, $p<0.001$ ), fibrinogen level (AUC $=0.759,95 \% \mathrm{CI}$ : $0.704-0.808, p<0.001)$, and PLT (AUC $=0.621,95 \% \mathrm{CI}$ : $0.562-0.678, p=0.01$ ) were effective predictors of inhospital mortality in children with moderate to severe TBI. We also performed ROC curve analysis of conventional coagulation tests for in-hospital mortality in the subgroup of isolated TBI patients (Table 5). The results 
Table 2 Demographics and clinical data of isolated TBI patients by survivors and non-survivors

\begin{tabular}{|c|c|c|c|c|}
\hline & $\begin{array}{l}\text { Isolated } \\
\text { TBI patients } \\
(n=137)\end{array}$ & $\begin{array}{l}\text { Survivors } \\
(n=118)\end{array}$ & $\begin{array}{l}\text { Non-survivors } \\
(n=19)\end{array}$ & $P$ value \\
\hline \multicolumn{5}{|l|}{ Baseline Demographics } \\
\hline Age, M & $36.0(12.5-79.0)$ & $45.0(13.0-80.0)$ & $17.0(11.0-58.0)$ & 0.112 \\
\hline Weight, kg & $15.0(10.0-22.0)$ & $15.5(10.0-23.0)$ & $12.0(9.0-15.0)$ & 0.117 \\
\hline Gender, male, n (\%) & $78(56.9 \%)$ & $69(58.5 \%)$ & $9(47.4 \%)$ & 0.456 \\
\hline \multicolumn{5}{|l|}{ Injury severity } \\
\hline GCS & $9(7-12)$ & $9(7-12)$ & $6(4-8)$ & 0.001 \\
\hline PTS & $6(4-8)$ & $7(4-8)$ & $4(2-6)$ & 0.001 \\
\hline ISS & $16(9-18)$ & $16(9-16)$ & $16(9-25)$ & 0.119 \\
\hline Mechanism of injury & & & & 0.668 \\
\hline Traffic, n (\%) & $43(31.4 \%)$ & 39 (33.1\%) & $4(21.1 \%)$ & \\
\hline Fall, n (\%) & $63(46.0 \%)$ & $54(45.8 \%)$ & $9(47.4 \%)$ & \\
\hline Others, n (\%) & $31(22.6 \%)$ & $25(21.2 \%)$ & $6(31.6 \%)$ & \\
\hline Abnormal pupil, n (\%) & $44(32.1 \%)$ & $28(23.7 \%)$ & 16 (84.2\%) & $<0.001$ \\
\hline Hypotension, n (\%) & $12(8.8 \%)$ & $9(7.6 \%)$ & $3(15.8 \%)$ & 0.373 \\
\hline \multicolumn{5}{|l|}{ Laboratory investigations } \\
\hline Lactate, $\mathrm{mmol} / \mathrm{L}$ & $1.4(0.8-3.4)$ & $1.2(0.7-2.7)$ & $4.4(2.8-8.3)$ & $<0.001$ \\
\hline INR & $1.12(1.03-1.24)$ & $1.11(1.03-1.20)$ & $1.22(1.09-1.49)$ & 0.027 \\
\hline APTT, s & $28.6(25.0-33.2)$ & $27.7(24.7-32.7)$ & $29.7(27.5-47.4)$ & 0.034 \\
\hline Fibrinogen, mg/dL & $\begin{array}{l}143.0 \\
(97.0-190.0)\end{array}$ & $\begin{array}{l}150.0 \\
(110.0-194.0)\end{array}$ & $\begin{array}{l}71.0 \\
(105.0-157.0)\end{array}$ & 0.024 \\
\hline$\pi, s$ & $18.4(17.3-21.2)$ & $18.3(17.1-20.7)$ & $18.9(17.9-22.1)$ & 0.082 \\
\hline D-dimer, ug/L & $\begin{array}{l}9810 \\
(2385-17,865)\end{array}$ & $\begin{array}{l}10,430 \\
(2413-18,458)\end{array}$ & $\begin{array}{l}5540 \\
(1570-16,600)\end{array}$ & 0.645 \\
\hline PLT, /uL & $\begin{array}{l}283.0 \\
(214.5-344.5)\end{array}$ & $\begin{array}{l}283.0 \\
(216.5-343.0)\end{array}$ & $\begin{array}{l}262.0 \\
(203.0-420.0)\end{array}$ & 0.830 \\
\hline $\mathrm{Hgb}, \mathrm{g} / \mathrm{L}$ & $\begin{array}{l}101.0 \\
(81.5-112.5)\end{array}$ & $\begin{array}{l}103.0 \\
(81.8-114.3)\end{array}$ & $\begin{array}{l}90.0 \\
(78.0-102.0)\end{array}$ & 0.044 \\
\hline WBC, ${ }^{*} 10 \wedge 9 / \mathrm{L}$ & $\begin{array}{l}15.7 \\
(11.9-21.1)\end{array}$ & $\begin{array}{l}15.7 \\
(11.9-21.0)\end{array}$ & $\begin{array}{l}14.3 \\
(11.4-21.7)\end{array}$ & 0.746 \\
\hline
\end{tabular}

Data are shown as the median (interquartile range) or a number (percentage)

$M$ month, GCS Glasgow Coma Score, PTS Pediatric Trauma Score, INR International normalized ratio, APTT activated partial thromboplastin time, $T T$ Thrombin time, PLT platelet count, Hgb hemoglobin, WBC white blood cell

showed that admission INR (AUC 0.659, 95 \%CI 0.497$0.821, P=0.027$ ), APTT (AUC 0.652, $95 \%$ CI 0.515$0.789, P=0.034$ ), fibrinogen (AUC 0.662, $95 \%$ CI 0.519 $0.805, P=0.024$ ) could also effectively predict the inhospital mortality. But the area under the curve was not as large as in the overall group.

\section{CART analysis for in-hospital mortality}

CART analysis was carried out using coagulation parameters, including the INR, APTT, TT, fibrinogen, and PLT, to predict mortality in children with TBI (Fig. 1). Consequently, APTT was identified as the best discriminator, with an optimal cut-off value of $39.2 \mathrm{~s} ; 120 \mathrm{mg} /$ $\mathrm{dL}$ fibrinogen was the second split in the subgroup of APTT $\leq 39.2 \mathrm{~s}$. As a result, patients were stratified into three groups: a low-risk group (group A) with APTT $\leq$ $39.2 \mathrm{~s}$ and fibrinogen $>120 \mathrm{mg} / \mathrm{dL}$, an intermediate-risk group (group B) with APTT $\leq 39.2 \mathrm{~s}$ and fibrinogen $\leq$ $120 \mathrm{mg} / \mathrm{dL}$, and a high- risk group (group C) with APTT $>39.2 \mathrm{~s}$. The mortality rates for groups A, B and C were $4.5 \%, 20.5$ and $60.8 \%$, respectively. The predictive accuracy of the CART model was $85.1 \%$, and the risk of misclassification was $18.9 \%$.

\section{Clinical characteristics of Group A, Group B and Group C established by CART}

The clinical characteristics of group A, group B and group $C$ are compared in Table 6. Compared with group $\mathrm{A}$ and $\mathrm{B}$, children in group $\mathrm{C}$ had significantly more 
Table 3 Comparison between isolated TBI patients and polytrauma patients

\begin{tabular}{|c|c|c|c|}
\hline & $\begin{array}{l}\text { Isolated TBI } \\
(n=137)\end{array}$ & $\begin{array}{l}\text { TBI + other } \\
(n=144)\end{array}$ & $P$ value \\
\hline \multicolumn{4}{|c|}{ Baseline Demographics } \\
\hline Age, $M$ & $36.0(12.5-79.0)$ & $60.5(29.3-96.0)$ & $<0.001$ \\
\hline Weight, kg & $15.0(10.0-22.0)$ & $19.5(13.6-25.0)$ & 0.001 \\
\hline Gender, male, n (\%) & 78 (56.9\%) & $92(63.9 \%)$ & 0.233 \\
\hline \multicolumn{4}{|l|}{ Injury severity } \\
\hline GCS & $9(7-12)$ & $7(5-8)$ & $<0.001$ \\
\hline PTS & $6(4-8)$ & $4(2-6)$ & $<0.001$ \\
\hline ISS & $16(9-17.5)$ & $25(18-34)$ & $<0.001$ \\
\hline Mechanism of injury & & & $<0.001$ \\
\hline Traffic, n (\%) & $43(31.4 \%)$ & $66(45.8 \%)$ & \\
\hline Fall, n (\%) & $63(46.0 \%)$ & $72(50.0 \%)$ & \\
\hline Others, n (\%) & $31(22.6 \%)$ & $6(4.2 \%)$ & \\
\hline Abnormal pupil & $44(32.1 \%)$ & 65 (45.1\%) & 0.028 \\
\hline Hypotension, n (\%) & $12(8.8 \%)$ & $22(15.3 \%)$ & 0.103 \\
\hline \multicolumn{4}{|c|}{ Laboratory investigations } \\
\hline Lactate, $\mathrm{mmol} / \mathrm{L}$ & $1.4(0.8-3.4)$ & $2.8(1.1-4.4)$ & 0.001 \\
\hline INR & $1.12(1.03-1.24)$ & $1.24(1.12-1.51)$ & $<0.001$ \\
\hline APTT, s & $28.6(25.0-33.2)$ & $30.4(27.4-39.2)$ & 0.001 \\
\hline Fibrinogen, mg/dL & $143.0(97.0-190.0)$ & $123.0(72.0-178.0)$ & 0.033 \\
\hline$\pi, s$ & $18.4(17.3-21.2)$ & $18.9(17.3-21.8)$ & 0.26 \\
\hline D-dimer, ug/L & $\begin{array}{l}9810 \\
(2385-17,865)\end{array}$ & $16,775(7098-28,523)$ & $<0.001$ \\
\hline PLT, /UL & $283.0(214.5-344.5)$ & 247.5 (167.8-299.5) & 0.001 \\
\hline $\mathrm{Hgb}, \mathrm{g} / \mathrm{L}$ & $101.0(81.5-112.5)$ & $98.0(81.3-110.0)$ & 0.283 \\
\hline WBC, ${ }^{*} 10 \wedge 9 / L$ & $15.7(11.9-21.1)$ & $13.1(12.7-22.0)$ & 0.120 \\
\hline
\end{tabular}

Data are shown as the median (interquartile range) or a number (percentage)

$M$ month, GCS Glasgow Coma Score, PTS Pediatric Trauma Score, ISS Injury Severity Score, INR International normalized ratio, APTT activated partial thromboplastin time, $T$ Thrombin time, PLT platelet count, Hgb hemoglobin, WBC white blood cell

severe injury scores. The proportions of polytrauma and hypotension in group $C$ were significantly higher than those in group A and B, respectively. Significantly elevated lactate and decreased $\mathrm{Hgb}$ were also observed in group $\mathrm{C}$ compared to groups $\mathrm{A}$ and $\mathrm{B}$. Increased in- hospital mortality and prolonged durations of mechanical ventilation and ICU stay were observed in groups B and $\mathrm{C}$ compared to group A. Additionally, decreased ventilator-free days, ICU-free days and hospital-free days were observed in groups $\mathrm{B}$ and $\mathrm{C}$ compared to group A.
Table 4 ROC curve analysis of conventional coagulation tests for in-hospital mortality in all TBI patients

\begin{tabular}{llll}
\hline Variables & AUC & $\mathbf{9 5} \% \mathbf{C l}$ & $\boldsymbol{P}$ \\
\hline INR & 0.770 & $0.716-0.818$ & $<0.001$ \\
APTT & 0.781 & $0.728-0.828$ & $<0.001$ \\
TT & 0.749 & $0.694-0.798$ & $<0.001$ \\
Fibrinogen & 0.759 & $0.704-0.808$ & $<0.001$ \\
PLT & 0.621 & $0.562-0.678$ & 0.01
\end{tabular}

$A U C$ area under the curve, $\mathrm{Cl}$ confidence interval, INR International normalized ratio, APTT activated partial thromboplastin time, $\Pi T$ Thrombin time, PLT platelet
Table 5 ROC curve analysis of conventional coagulation tests for in-hospital mortality in isolated TBI patients

\begin{tabular}{llll}
\hline Variables & AUC & $\mathbf{9 5} \% \mathbf{C l}$ & $\boldsymbol{P}$ \\
\hline INR & 0.659 & $0.497-0.821$ & 0.027 \\
APTT & 0.652 & $0.515-0.789$ & 0.034 \\
$T T$ & 0.624 & $0.489-0.759$ & 0.082 \\
Fibrinogen & 0.662 & $0.519-0.805$ & 0.024 \\
PLT & 0.485 & $0.327-0.642$ & 0.830 \\
\hline
\end{tabular}

AUC area under the curve, $C l$ confidence interval, INR International normalized ratio, APTT activated partial thromboplastin time, $\pi$ Thrombin time, $P L T$ platelet 
Table 6 Comparison of clinical characteristics among groups A, B and C

\begin{tabular}{|c|c|c|c|c|c|c|c|}
\hline & Group A & Group B & Group C & $P^{a}$ & Pairwise & parisons & \\
\hline & & & & & $A \vee B$ & $A \vee C$ & B v C \\
\hline Age, M & $\begin{array}{l}60.0 \\
(23.0-95.5)\end{array}$ & $\begin{array}{l}36.0 \\
(14.5-88.0)\end{array}$ & $\begin{array}{l}37.0 \\
(21.0-78.0)\end{array}$ & 0.056 & & & \\
\hline Males, n (\%) & $\begin{array}{l}90 \\
(57.3 \%)\end{array}$ & $\begin{array}{l}48 \\
(65.8 \%)\end{array}$ & $\begin{array}{l}32 \\
(62.7 \%)\end{array}$ & 0.446 & & & \\
\hline Weight, kg & $\begin{array}{l}18.0 \\
(12.3-25.0)\end{array}$ & $\begin{array}{l}16.0 \\
(10.5-22.0)\end{array}$ & $\begin{array}{l}15.0 \\
(10.0-20.0)\end{array}$ & 0.073 & & & \\
\hline GCS & $8(7-12)$ & $8(6-9)$ & $5(3-7)$ & $<0.001$ & 0.038 & $<0.001$ & $<0.001$ \\
\hline PTS & $6(4-8)$ & $4(3-6)$ & $2(1-3)$ & $<0.001$ & 0.003 & $<0.001$ & $<0.001$ \\
\hline ISS & $18(9-25)$ & $18(12-29)$ & $25(18-34)$ & $<0.001$ & 0.333 & $<0.001$ & 0.067 \\
\hline Polytrauma,n (\%) & 72 (45.9\%) & 37 (50.7\%) & 35 (68.6\%) & 0.018 & & & \\
\hline Hypotension,n(\%) & $6(3.8 \%)$ & $10(13.7 \%)$ & 18 (35.5\%) & $<0.001$ & & & \\
\hline Lactate, $\mathrm{mmol} / \mathrm{L}$ & $1.3(0.7-2.8)$ & $2.8(1.1-4.4)$ & $4.9(2.9-7.1)$ & $<0.001$ & $<0.001$ & $<0.001$ & 0.001 \\
\hline $\mathrm{Hgb}, \mathrm{g} / \mathrm{L}$ & $106(92-118)$ & $92(79-105)$ & $76(55-85)$ & $<0.001$ & $<0.001$ & $<0.001$ & 0.001 \\
\hline Death, n (\%) & $7(4.5 \%)$ & 15 (20.5\%) & 31 (60.8\%) & $<0.001$ & & & \\
\hline HLOS, d & $20(12-37)$ & $20(12-34)$ & $6(1-25)$ & $<0.001$ & 1 & $<0.001$ & 0.001 \\
\hline Hospital-free days, d & $7(0-15)$ & $2(0-12)$ & $0(0-0)$ & $<0.001$ & 0.148 & $<0.001$ & $<0.001$ \\
\hline ILOS, d & $2(1-5)$ & $4(1-11)$ & $4(1-9)$ & 0.01 & 0.017 & 0.146 & 1 \\
\hline ICU-free days, d & $12(9-13)$ & $7(0-13)$ & $0(0-1)$ & $<0.001$ & $<0.001$ & $<0.001$ & $<0.001$ \\
\hline Intubation days, $\mathrm{d}$ & $1(1-2)$ & $2(1-6)$ & $2(1-6)$ & $<0.001$ & $<0.001$ & 0.001 & 1 \\
\hline Intubation-free days, d & $13(11-13)$ & $6(0-10)$ & $0(0-0)$ & $<0.001$ & $<0.001$ & $<0.001$ & $<0.001$ \\
\hline
\end{tabular}

Data are shown as the median (interquartile range) or a number (percentage)

M month, GCS Glasgow Coma Score, PTS Pediatric Trauma Score, ISS Injury Severity Score, Hgb hemoglobin, HLOS hospital length-of-stay, ICU intensive care unit, ILOS ICU length-of-stay

${ }^{a}$ Kruskal-Wallis or Chi-square test for continuous or categorical variables, respectively

However, the LOS in hospital in group $\mathrm{C}$ was less than in groups A and B, which may due to the higher mortality rate of group $C$.

\section{Multivariate logistic regression analysis for mortality}

Based on the cut-off value from the CART analysis, multivariate logistic regression analysis was performed to assess the effect of abnormal coagulation parameters, including APTT $>39.2 \mathrm{~s}$, fibrinogen $\leq 120 \mathrm{mg} / \mathrm{dL}$, hypotension, GCS $\leq 8, \mathrm{ISS} \geq 16, \mathrm{Hgb}<90 \mathrm{~g} / \mathrm{L}$, lactate $>2$ $\mathrm{mmol} / \mathrm{L}$, polytrauma and abnormal pupil. Consequently, we concluded that APTT $>39.2$ s $(\mathrm{OR}=13.189,95 \%$ CI4.101-42.411, $\quad P<0.001), \quad$ fibrinogen $\leq 120 \quad \mathrm{mg} / \mathrm{dL}$ $(\mathrm{OR}=3.871,95 \% \mathrm{CI} 1.443-10.388, P=0.007)$, and abnormal pupil $(\mathrm{OR}=16.680,95 \%$ CI5.405-51.474, $P<0.001)$ were independently associated with in-hospital mortality in the overall TBI patients (Table 7).

\section{Discussion}

Coagulation disorders after TBI can refer to the disruption of the balance between coagulation and anticoagulation after injury [14]. The proposed mechanisms that trigger hemostatic disorders after TBI are still complex and controversial. The most widely accepted hypothesis is the activation of tissue factors, which are released from the damaged brain and lead to the depletion of coagulation factors [15]. Endothelial activation, protein $C$ pathway activation, and endogenous plasminogen activator release were also found to contribute to the occurrence of coagulopathy in TBI patients [16-18].

In our analysis, children with APTT $>39.2 \mathrm{~s}$ or fibrinogen $\leq 120 \mathrm{mg} / \mathrm{dL}$ were more likely to present with lower GCS and PTS and higher ISS, consistent with other studies on patients with TBI $[5,19]$. Joseph et al. [19] defined coagulopathy as a prolonged INR and APTT or a decreased platelet count and found that adult TBI patients with coagulopathy were more likely to present with a lower GCS score and higher ISS. Talving et al. [20] identified GCS $\leq 8$ and ISS $\geq 16$ as independent risk factors for the development of coagulopathy in adult TBI patients. However, to the best of our knowledge, there is limited research that has explored the relationship between PTS and coagulopathy presentation. According to our study, a lower PTS was also associated with deteriorated APTT or fibrinogen values, similar to GCS and ISS.

We found that the occurrence of hypotension was significantly higher in TBI children with deteriorated APTT or fibrinogen values. Serum lactate is a by-product of 


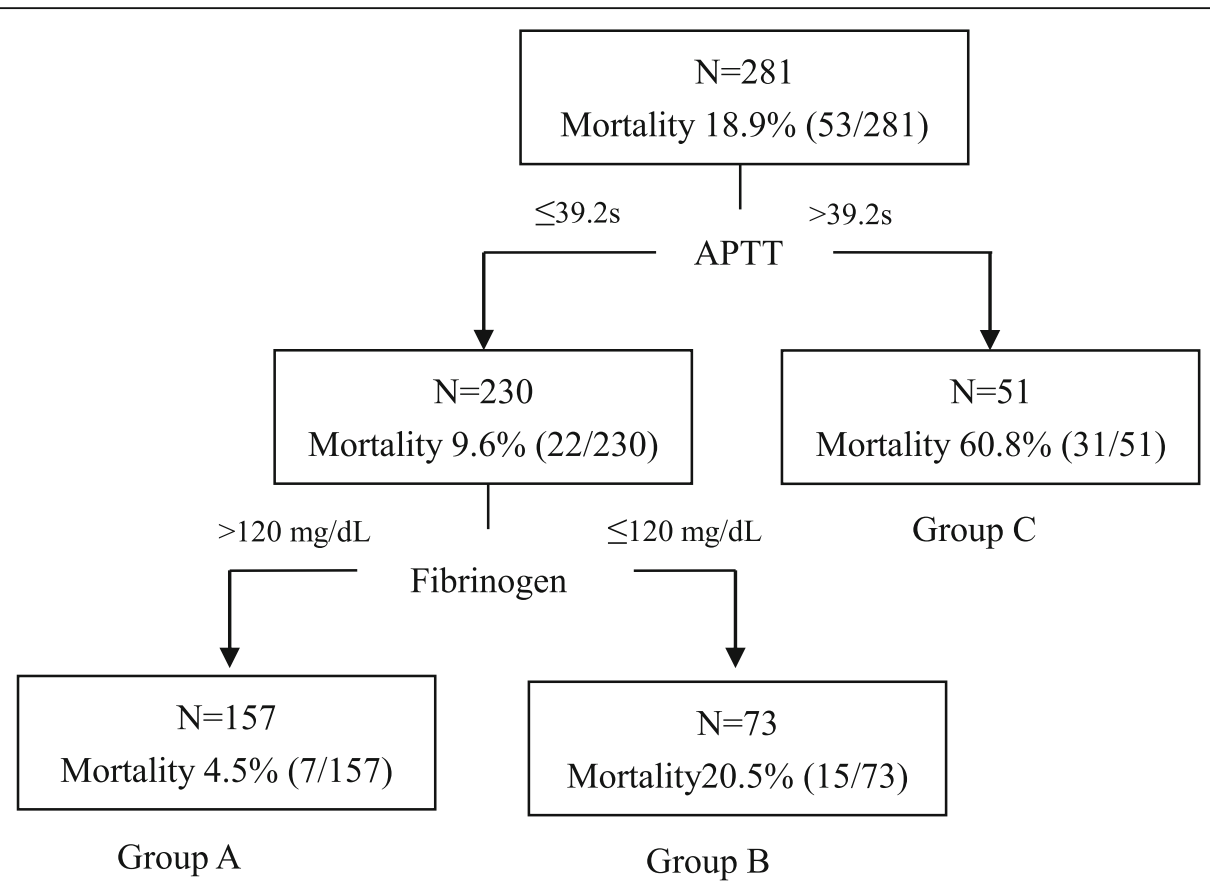

Fig. 1 CART prediction model for mortality in children with moderate to severe TBI. The selected splitting variables (APTT of $39.2 \mathrm{~s}$ and fibrinogen of $120 \mathrm{mg} / \mathrm{dL}$ ) are shown in the nodes. Three groups were established: group A (APTT $\leq 39.2 \mathrm{~s}$, fibrinogen $>120 \mathrm{mg} / \mathrm{dL}, n=157$ ), group B (APTT $\leq 39.2 \mathrm{~s}$, fibrinogen $\leq 120 \mathrm{mg} / \mathrm{dL}, n=73$ ) and group C (APTT $>39.2 \mathrm{~s}, n=51$ ). APTT, activated partial thromboplastin time

anaerobic metabolism and is always used as a marker of tissue hypoperfusion. In a previous study, we demonstrated that admission serum lactate could effectively predict mortality in children with moderate to severe TBI [21]. Moreover, in the present study, serum lactate was greatly increased in patients with abnormal APTT or fibrinogen. Lactate may be closely related to coagulation dysfunction in patients with TBI. Simone et al. [22] demonstrated that TBI patients with acute coagulopathy had a higher lactate level than patients without coagulopathy and that increased lactate levels significantly correlated with decreased fibrinogen levels and increased D-dimers. However, Hayakawa et al. [7] found that the increase in lactate level was correlated with the impairment of coagulation and fibrinolytic parameters in the non-TBI group only; no such correlation was observed in the TBI group. Therefore, in children with traumatic brain injury, the relationship between the early lactate level and coagulation dysfunction requires further study.

APTT can sensitively reflect the consumption and/or dysfunction of factors XI, IX, and VIII [23]. APTT is commonly used to define coagulation dysfunction and is significantly associated with a poor clinical outcome in TBI patients [2, 5]. Nakae et al. [24] found that upward trends of APTT on admission and $3 \mathrm{~h}$ after injury were significant negative prognostic indicators in TBI patients,

Table 7 Multivariate logistic regression analysis in all TBI patients to identify risk factors at admission related to mortality

\begin{tabular}{|c|c|c|c|c|}
\hline Variate & $\begin{array}{l}\text { Univariate logistic regression } \\
\text { unadjusted OR }(95 \% \mathrm{Cl})\end{array}$ & $P$ value & $\begin{array}{l}\text { Multivariate logistic regression } \\
\text { adjusted OR }(95 \% \mathrm{Cl})\end{array}$ & $P$ value \\
\hline $\mathrm{APTT}>39.2 \mathrm{~s}$ & $14.655(7.180-29.911)$ & $<0.001$ & $13.189(4.101-42.411)$ & $<0.001$ \\
\hline Fibrinogen $\leq 120 \mathrm{mg} / \mathrm{dL}$ & 8.107 (3.947-16.652) & $<0.001$ & $3.871(1.443-10.388)$ & 0.007 \\
\hline Hypotension & 4.342 (2.030-9.286) & $<0.001$ & $0.783(0.232-2.642)$ & 0.694 \\
\hline $\mathrm{GCS} \leq 8$ & $5.905(2.427-14.369)$ & $<0.001$ & $1.130(0.344-3.707)$ & 0.840 \\
\hline ISS $\geq 16$ & $2.391(1.070-5.341)$ & 0.034 & $0.640(0.195-2.103)$ & 0.462 \\
\hline Lactate $>2 \mathrm{mmol} / \mathrm{l}$ & $13.544(5.190-35.344)$ & $<0.001$ & $2.657(0.836-8.444)$ & 0.098 \\
\hline $\mathrm{Hgb}<90 \mathrm{~g} / \mathrm{L}$ & $3.116(1.686-5.758)$ & $<0.001$ & $0.515(0.181-1.463)$ & 0.213 \\
\hline Abnormal pupil & $20.973(8.541-51.502)$ & $<0.001$ & $16.680(5.405-51.474)$ & $<0.001$ \\
\hline Polytrauma & $1.920(1.034-3.563)$ & 0.039 & $0.865(0.328-2.281)$ & 0.769 \\
\hline
\end{tabular}

OR odds ratio, $\mathrm{Cl}$ confidence interval, APTT activated partial thromboplastin time, GCS Glasgow Coma Score, ISS Injury Severity Score, Hgb hemoglobin 
and multivariate logistic regression analysis identified that APTT $>30.2 \mathrm{~s}$ was an independent risk factor for poor prognosis. In our analysis, ROC curve analysis showed that admission APTT can effectively predict mortality in children with moderate to severe TBI, and according to CART analysis, APTT was the optimal coagulation parameter to predict mortality and APTT > $39.2 \mathrm{~s}$ was independently associated with mortality after adjusting to other potential confounding factors. We argue that the APTT value at admission may potentially be useful as a predictor of mortality, which may help clinicians to better assess the severity of injury and take specific interventions to improve the prognosis of children with moderate to severe TBI.

Decreased fibrinogen is associated with deleterious effects for TBI. Tareq et al. [25] found that TBI patients in the $\mathrm{PICH}$ group showed a higher rate of decreased fibrinogen (fibrinogen level $<2 \mathrm{~g} / \mathrm{L}$ ) than patients in the non-PICH group. When the fibrinogen level was $<2 \mathrm{~g} / \mathrm{L}$ at arrival, a PICH progression was three-times more likely to occur. Nakae et al. [26] revealed that among patients with TBI who did not receive a fresh frozen plasma transfusion, a fibrinogen level $<150 \mathrm{mg} / \mathrm{dL}$ at $3 \mathrm{~h}$ after injury was significantly associated with a higher duration of mechanical ventilation and lower GOS scores at discharge and 3 months after injury. From the CART analysis in the present study, we concluded that TBI patients in group B with normal APTT and decreased fibrinogen $(\leq 120 \mathrm{mg} / \mathrm{dL})$ had increased inhospital mortality, prolonged LOS in the ICU and hospital, and shortened ventilator-free days, ICU-free days, and hospital-free days than patients in group A, which indicated that fibrinogen was also an important coagulation parameter associated with poor outcome.

In addition to APTT and fibrinogen, other coagulation parameters were also found to significantly associate with mortality in TBI patients. Christian et al. [27] found that radiologic and clinical deterioration of TBI patients was significantly associated with an elevated INR. Joseph et al. [19] reported that a platelet count of $100 \times 10^{3} / \mathrm{uL}$ or less was the strongest predictor of progression of the initial insult in repeat head computed tomography, need for neurosurgical intervention, and mortality in TBI patients. In the present study, we found that the platelet counts in the survivors and non-survivors were in the normal range, but the median platelet count was significantly lower in the non-survivor group, but this change was not observed in the subgroup of isolated TBI patients. We also observed that INR was significantly elevated in non-survivors compared to survivors and ROC curve analysis showed that INR could effectively predict mortality in children with TBI.

There were several limitations in our study. First, this is a single-center retrospective study. Since the sample size of isolated TBI patients in our study is relatively small, the stability of CART is limited. We only performed CART analysis and multivariate logistic regression analysis in the overall group and further multicenter researches is needed to explore the predictive value of admission coagulopathy for mortality in children with isolated TBI. Second, we did not evaluate the impact of the treatment of coagulation disorders on the outcome during hospitalization, such as the use of fresh frozen plasma, cryoprecipitate or platelets. Third, we only studied the impact of blood biomarkers collected at the time of admission on the prognosis of patients. The coagulation parameters at other time points after admission were not explored. Finally, we regard in-hospital mortality as the primary outcome, but longer-term functional outcomes were not evaluated.

\section{Conclusions}

Based on our study, the presence of admission of APTT $>39.2 \mathrm{~s}$ and fibrinogen $\leq 120 \mathrm{mg} / \mathrm{dL}$ were independently associated with increased in-hospital mortality in pediatric TBI patients. Early identification and intervention of abnormal APTT and fibrinogen in pediatric TBI patients may be beneficial to their prognosis.

\section{Acknowledgements \\ Not applicable.}

\section{Authors' contributions}

YF conceived the study and coordinated and finalized the manuscript. FX participated in the coordination. CY participated in the design, data acquisition, database management, statistical analysis and preparation of the manuscript draft. SL participated in the analysis and database management. YF takes responsibility for the article as a whole. The author(s) read and approved the final manuscript.

\section{Funding}

This study was supported by Natural Science Foundation Project of Chongqing of China (No. cstc2020jcyj-msxmX1087).

\section{Availability of data and materials}

Anonymized data analyzed for the current study will be shared if a reasonable request is made by a qualified investigator to the corresponding author.

\section{Declarations}

\section{Ethics approval and consent to participate}

Ethical approval was obtained from the Institutional Ethics Review Board of Children's Hospital, Chongqing Medical University. The need for informed consent was waived due to the anonymous and observational nature of this study.

\section{Consent for publication}

Not applicable.

\section{Competing interests}

The authors declare that they have no conflicts of interest.

\section{Author details}

'Department of Critical Care Medicine, Children's Hospital, Chongqing Medical University, 136\# Zhongshan Er Road, Yu Zhong District, 400014 Chongqing, People's Republic of China. ${ }^{2}$ Ministry of Education Key Laboratory of Child Development and Disorders, 400014 Chongqing, 
People's Republic of China. ${ }^{3}$ National Clinical Research Center for Child Health and Disorders, 400014 Chongqing, People's Republic of China. ${ }^{4}$ China International Science and Technology Cooperation base of Child development and Critical Disorders, 400014 Chongqing, People's Republic of China. ${ }^{5}$ Chongqing Key Laboratory of Pediatrics, 400014 Chongqing, People's Republic of China.

Received: 19 February 2021 Accepted: 10 May 2021

Published online: 20 May 2021

\section{References}

1. Sarnaik A, Ferguson NM, O'Meara AMl, Agrawal S, Deep A, Buttram S, et al. Age and portality in pediatric severe traumatic brain injury: results from an international study. Neurocrit Care. 2018;28(3):302-13.

2. Chhabra G, Sharma S, Subramanian A, Agrawal D, Sinha S, Mukhopadhyay AK. Coagulopathy as prognostic marker in acute traumatic brain injury. J Emerg Trauma Shock. 2013;6(3):180-5.

3. Dwivedi AK, Sharma A, Sinha VD. Comparative study of derangement of coagulation profile between adult and pediatric population in moderate to severe traumatic brain injury: a prospective study in a tertiary care trauma center. Asian J Neurosurg. 2018;13(4):1123-7.

4. Shrestha A, Joshi RM, Devkota UP. Contributing factors for coagulopathy in traumatic brain injury. Asian J Neurosurg. 2017;12(4):648-52.

5. Abdelmalik PA, Boorman DW, Tracy J, Jallo J, Rincon FJNC. Acute traumatic coagulopathy accompanying isolated traumatic brain injury is associated with worse long-term functional and cognitive outcomes. Neurocrit Care. 2015;24(3):1-10.

6. Fair K, Farrell D, McCully B, Rick E, Dewey EN, Hilliard C, et al. Fibrinolytic activation in patients with progressive intracranial hemorrhage after traumatic brain injury. J Neurotrauma. 2021:38(8):960-6.

7. Hayakawa M, Maekawa K, Kushimoto S, Kato H, Sasaki J, Ogura H, et al. Hyperfibrinolysis in severe isolated traumatic brain injury may occur without tissue hypoperfusion: a retrospective observational multicentre study. Crit Care. 2017;21(1):222

8. Albert V, Arulselvi S, Agrawal D, Pati HP, Pandey RM. Early posttraumatic changes in coagulation and fibrinolysis systems in isolated severe traumatic brain injury patients and its influence on immediate outcome. Hematol Oncol Stem Cell Ther. 2019;12(1):32-43.

9. Strumwasser A, Speer AL, Inaba K, Branco BC, Upperman JS, Ford HR, et al. The impact of acute coagulopathy on mortality in pediatric trauma patients. J Trauma Acute Care Surg. 2016:81(2):312-8.

10. Whittaker B, Christiaans SC, Altice JL, Chen MK, Bartolucci AA, Morgan CJ, et al. Early coagulopathy is an independent predictor of mortality in children after severe trauma. Shock. 2013;39(5):421-6.

11. Tepas JJ 3rd, Mollitt DL, Talbert JL, Bryant M. The pediatric trauma score as a predictor of injury severity in the injured child. J Pediatr Surg. 1987;22(1):148.

12. Kleinman ME, Chameides L, Schexnayder SM, Samson RA, Hazinski MF, Atkins DL, et al. Part 14: pediatric advanced life support: 2010 American heart association guidelines for cardiopulmonary resuscitation and emergency cardiovascular care. Circulation. 2010;122(18 Suppl 3):876-908.

13. N S. Classification and regression trees. Health Int J Public Health. 2012;1 (1): 14-23.

14. Maegele M, Schöchl H, Menovsky T, Maréchal H, Marklund N, Buki A, et al. Coagulopathy and haemorrhagic progression in traumatic brain injury: advances in mechanisms, diagnosis, and management. Lancet Neurol. 2017; 16(8):630-47.

15. Salehi A, Zhang $\mathrm{JH}$, Obenaus A. Response of the cerebral vasculature following traumatic brain injury. J Cereb Blood Flow Metab. 2017;37(7): 2320-39.

16. Di Battista AP, Rhind SG, Hutchison MG, Hassan S, Shiu MY, Inaba K, et al. Inflammatory cytokine and chemokine profiles are associated with patient outcome and the hyperadrenergic state following acute brain injury. J Neuroinflammation. 2016;13:40

17. Di Battista AP, Rizoli SB, Lejnieks B, Min A, Shiu MY, Peng HT, et al. Sympathoadrenal activation is associated with acute traumatic coagulopathy and endotheliopathy in isolated brain injury. Shock. 2016;46(3 Suppl 1):96-103.

18. Cohen MJ, Brohi K, Ganter MT, Manley GT, Mackersie RC, Pittet JF. Early coagulopathy after traumatic brain injury: the role of hypoperfusion and the protein C pathway. J Trauma. 2007;63(6):1254-61. discussion 61 - 2 .
19. Joseph B, Aziz H, Zangbar B, Kulvatunyou N, Pandit V, O'Keeffe T, et al. Acquired coagulopathy of traumatic brain injury defined by routine laboratory tests: which laboratory values matter? I Trauma Acute Care Surg. 2014;76(1):121-5.

20. Talving P, Benfield R, Hadjizacharia P, Inaba K, Chan LS, Demetriades D. Coagulopathy in severe traumatic brain injury: a prospective study. J Trauma. 2009;66(1):55-61. discussion - 2.

21. Fu YQ, Bai K, Liu CJ. The impact of admission serum lactate on children with moderate to severe traumatic brain injury. PLoS One. 2019;14(9): e0222591.

22. Dekker SE, Duvekot A, de Vries HM, Geeraedts LM Jr, Peerdeman SM, de Waard MC, et al. Relationship between tissue perfusion and coagulopathy in traumatic brain injury. J Surg Res. 2016;205(1):147-54.

23. Laroche M, Kutcher ME, Huang MC, Cohen MJ, Manley GT. Coagulopathy after traumatic brain injury. Neurosurgery. 2012:70(6):1334-45.

24. Nakae R, Takayama Y, Kuwamoto K, Naoe Y, Sato H, Yokota H. Time course of coagulation and fibrinolytic parameters in patients with traumatic brain injury. J Neurotrauma. 2016;33(7):688-95.

25. Juratli TA, Zang B, Litz RJ, Sitoci KH, Aschenbrenner U, Gottschlich B, et al. Early hemorrhagic progression of traumatic brain contusions: frequency, correlation with coagulation disorders, and patient outcome: a prospective study. J Neurotrauma. 2014;31(17):1521-7.

26. Nakae R, Yokobori S, Takayama Y, Kanaya T, Fujiki Y, Igarashi Y, et al. A retrospective study of the effect of fibrinogen levels during fresh frozen plasma transfusion in patients with traumatic brain injury. Acta Neurochir (Wien). 2019:161(9):1943-53.

27. von der Brelie C, Schneegans I, van den Boom L, Meier U, Hedderich J, Lemcke J. Impaired coagulation is a risk factor for clinical and radiologic deterioration in patients with traumatic brain injury and isolated traumatic subarachnoid hemorrhage. J Trauma Acute Care Surg. 2015;79(2):295-300.

\section{Publisher's Note}

Springer Nature remains neutral with regard to jurisdictional claims in published maps and institutional affiliations.

Ready to submit your research? Choose BMC and benefit from:

- fast, convenient online submission

- thorough peer review by experienced researchers in your field

- rapid publication on acceptance

- support for research data, including large and complex data types

- gold Open Access which fosters wider collaboration and increased citations

- maximum visibility for your research: over $100 \mathrm{M}$ website views per year

At BMC, research is always in progress.

Learn more biomedcentral.com/submissions 